\title{
Total dietary antioxidant capacity and risk of type 2 diabetes
}

\author{
Niels van der Schaft ${ }^{1} \cdot$ Trudy Voortman $^{1}$
}

Received: 10 February 2020 / Accepted: 24 February 2020 / Published online: 5 March 2020

(c) Springer Nature B.V. 2020

We extend our gratitude to Dr Kawada for the comments on our paper on total dietary antioxidant capacity (TAC) and risk of type 2 diabetes [1,2].

The author remarks that risk assessment for type 2 diabetes in relation to coffee intake must be precisely reviewed in light of our finding that the association between TAC and risk of type 2 diabetes was, to an extent, driven by the contribution of coffee intake to TAC. Indeed, coffee contributed to $49 \%$ of TAC in our study and is therefore one of the most important sources of antioxidants in the diet of our study population. Given the widely documented health benefits of antioxidants, we hypothesize that the previously reported protective associations between coffee consumption and risk of type 2 diabetes might to no small degree be driven by the antioxidants contained in coffee [3, 4].

We agree with Dr Kawada that that the association between TAC and non-communicable diseases of both physical and psychiatric nature is an important topic that merits further investigation. Building upon the findings with relation to risk of type 2 diabetes, previous studies have also demonstrated that higher TAC is also associated with lower risk of myocardial infarction [5, 6]. Other studies have investigated TAC in relation to cause-specific and allcause mortality, but the results of these studies have not been unequivocal [7, 8]. Similarly, studies on TAC and incident stroke have reported conflicting results $[9,10]$. Furthermore, as highlighted in the letter by Dr Kawada, there have been some studies that investigated TAC with outcomes related to psychiatric illness, although there is a paucity of longitudinal studies on this topic. Taken together, the studies on TAC and health-related outcomes suggest that a dietary pattern rich in antioxidants could be an important and modifiable determinant of a wide range of physical and mental diseases, but further well-designed studies are needed to better understand

Trudy Voortman

trudy.voortman@erasmusmc.nl

1 Department of Epidemiology, Erasmus University Medical Center, Rotterdam, The Netherlands its properties as a risk factor and the corresponding pathophysiological pathways.

\section{References}

1. Kawada T. Total dietary antioxidant capacity and risk of type 2 diabetes. Eur J Epidemiol. 2020.

2. van der Schaft N, Schoufour JD, Nano J, et al. Dietary antioxidant capacity and risk of type 2 diabetes mellitus, prediabetes and insulin resistance: the Rotterdam Study. Eur J Epidemiol. 2019;34:853-61.

3. Mirmiran P, Carlström M, Bahadoran Z, Azizi F. Long-term effects of coffee and caffeine intake on the risk of pre-diabetes and type 2 diabetes: findings from a population with low coffee consumption. Nutr Metab Cardiovas Dis NMCD. 2018;28:1261-6.

4. Bhupathiraju SN, Pan A, Manson JE, Willett WC, van Dam RM, $\mathrm{Hu} \mathrm{FB}$. Changes in coffee intake and subsequent risk of type 2 diabetes: three large cohorts of US men and women. Diabetologia. 2014;57:1346-54.

5. Hantikainen E, Löf M, Grotta A, et al. Dietary non enzymatic antioxidant capacity and the risk of myocardial infarction in the Swedish women's lifestyle and health cohort. Eur J Epidemiol. 2018;33:213-21.

6. Rautiainen S, Levitan EB, Orsini N, et al. Total antioxidant capacity from diet and risk of myocardial infarction: a prospective cohort of women. Am J Med. 2012;125:974-80.

7. Bastide N, Dartois L, Dyevre V, et al. Dietary antioxidant capacity and all-cause and cause-specific mortality in the E3N/EPIC cohort study. Eur J Nutr. 2017;56:1233-43.

8. Henríquez-Sánchez P, Sánchez-Villegas A, Ruano-Rodríguez $\mathrm{C}$, et al. Dietary total antiox-idant capacity and mortality in the PREDIMED study. Eur J Nutr. 2016;55:227-36.

9. Colarusso L, Serafini M, Lagerros YT, et al. Dietary antioxidant capacity and risk for stroke in a prospective cohort study of swedish men and women. Nutrition (Burbank, Los Angeles County, Calif.). 2017;33:234-9.

10. Devore EE, Feskens E, Ikram MA, et al. Total antioxidant capacity of the diet and major neurologic outcomes in older adults. Neurology. 2013;80:904-10.

Publisher's Note Springer Nature remains neutral with regard to jurisdictional claims in published maps and institutional affiliations. 